\title{
A CONTRIBUIÇÃO DO GENE HALOTANO SOBRE AS CARACTERÍSTICAS DE QUALIDADE DA CARNE SUÍNA ${ }^{1}$
}

\author{
THE CONTRIBUTION OF THE HALOTHANE GENE TO THE QUALITY \\ CHARACTERISTICS OF PORK
}

\author{
Paulete de Oliveira Vargas Culau ${ }^{2}$ Jorge López $^{3}$ Jane Maria Rubensam $^{4}$ \\ Rui Fernando Félix Lopes ${ }^{5}$ Sérgio Nicolaiewsky ${ }^{6}$
}

RESUMO

O objetivo deste trabalho foi o de avaliar o efeito do gene halotano sobre as características de qualidade da carne suína. Foram utilizadas 151 carcaças de suínos híbridos comerciais, sendo 93 carcaças com genótipo halotano normal $\left(\mathrm{Hal}^{\mathrm{NN}}\right), 51$ heterozigotos $\left(\mathrm{Hal}^{\mathrm{Nn}}\right)$ e 7 recessivas $\left(\mathrm{Hal}^{n n}\right)$. As medidas efetuadas foram: espessura de toucinho e de músculo, percentagem de carne, peso da carcaça, pH aos 45 minutos e 24 horas após o abate, no músculo Longissimus dorsi, cor, perda de líquido por gotejamento e identificação do genótipo halotano em amostras de gordura através de PCR-RFLP. Suínos Hal ${ }^{N}$ apresentaram maior espessura de músculo e percentagem de carne do que os suínos $\mathrm{Hal}^{N N}$. Houve diferença significativa entre suínos $\mathrm{Hal}^{\mathrm{Nn}}$ e Hal $\mathrm{H}^{N N}$ quanto ao $\mathrm{pH}$ inicial e à cor. Em relação à espessura de toucinho, pH final e perda de líquido, não houve diferença significativa entre os genótipos. A qualidade da carne de suínos $\mathrm{Hal}^{\mathrm{Nn}}$ foi inferior à de suínos $\mathrm{Hal}^{N N}$, em termos de $\mathrm{pH}$ e cor. A qualidade da carcaça de suínos $\mathrm{Hal}^{\mathrm{Nn}}$ não se mostrou melhor do que a dos suínos $\mathrm{Hal}^{n n}$, em relação à espessura de toucinho e músculo e à percentagem de carne. A relação entre quantidade e qualidade da carne parece depender da presença do gene halotano.

Palavras-chave: gene halotano, PSE, qualidade da carne suína.

\section{SUMMARY}

The aim of this research work was to evaluate the effect of the halothane gene on the quality characteristics of pork. Commercial hybrid pig carcasses (151) were used for the trial, 93 with normal halothane genotype $\left(\mathrm{Hal}^{N N}\right), 51$ heterozygous genotype $\left(\mathrm{Hal}^{\mathrm{Nn}}\right)$ and 7 homozigous recessive genotype $\left(\mathrm{Hal}^{n n}\right)$.
The measured attributes were backfat and muscle depth, meat percentage, carcass weight and $\mathrm{pH}$ at 45 minutes and 24 hours after the slaughter, on the Longissimus dorsi muscle, color, drip loss, and identification of the halothane genotype was determined in fat samples through PCR-RFLP technique. The Hal ${ }^{N n}$ pigs presented greater muscle depth and meat percentage than Hal ${ }^{N N}$ ones. Significant differences were observed between $\mathrm{Hal}^{\mathrm{Nn}}$ and $\mathrm{Hal}^{N N}$ pigs in relation to the inicial $\mathrm{pH}$ and meat color. The halothane genotype did not affect the backfat thickness, final pH and water holding capacity. Differences between carcass quality from the $\mathrm{Hal}^{\mathrm{Nn}}$ and the nn pigs in relation to the backfat thickness, muscle depth and the meat percentage were not observed. Differences between quantity and quality of pork seems to be associated to the presence of the halothane gene.

Key words: halothane gene, PSE, pork quality.

\section{INTRODUÇÃO}

Foi descoberta uma mutação no gene que codifica para o receptor rianodina do músculo esquelético, correlacionada com a hipertermia maligna. Um teste não invasivo, foi desenvolvido baseado em PCR-RFLP (reação em cadeia de polimerase - polimorfismos do comprimento dos fragmentos de restrição), que permite diferenciar três genótipos $\left(\mathrm{Hal}^{\mathrm{NN}}, \mathrm{Hal}^{\mathrm{Nn}}\right.$ e $\left.\mathrm{Hal}^{\mathrm{nn}}\right)$, tornando possível fazer estudos de freqüência do gene halotano, nas diferentes raças de suínos, para que melhores

\footnotetext{
${ }^{1}$ Parte da tese de doutorado em Zootecnia do primeiro autor, Faculdade de Agronomia (FA), Universidade Federal do Rio Grande do Sul (UFRGS), Porto Alegre, RS.

${ }_{2}^{2}$ Médico Veterinário, Doutor, Professor Adjunto, Departamento de Ciências Morfológicas (DCM), Instituto de Ciências Básica da Saúde (ICBS),

UFRGS. Faculdade de Veterinária (FV), Av. Bento Gonçalves/9090. E-mail: anavet@ vortex.ufrgs.br. Autor para correspondência.

${ }^{3}$ Engenheiro Agrônomo, PhD., Professor Titular, Departamento de Zootecnia (DZ), FA, UFRGS. Bolsista do CNPq.

${ }^{4}$ Médico Veterinário, Doutor, Professor Adjunto, Departamento de Medicina Veterinária Preventiva, FV, UFRGS.

${ }^{5}$ Médico Veterinário, Doutor, Professor Adjunto, DCM, ICBS, UFRGS.

${ }^{6}$ Engenheiro Agrônomo, Mestre, Professor Adjunto, DZ, FA, UFRGS.
} 
estratégias de cruzamentos sejam traçadas (FUJII $\boldsymbol{e t}$ al., 1991).

O gene halotano, além de determinar a maior predisposição a Síndrome do Estresse em suínos, é responsável por carcaças com maior proporção de carne magra, mas relacionado à produção de carne PSE (do inglês: pale, soft and exudative) um problema grave para a industrialização de carnes. $O$ gene halotano não somente afeta a qualidade da carne de suínos homozigotos recessivos $\left(\mathrm{Hal}^{\mathrm{nn}}\right)$, como também afeta a qualidade da carne de carcaças suínas heterozigotas $\mathrm{Hal}^{\mathrm{Nn}}$ (SATHER et al., 1991).

Os suínos heterozigotos apresentam um rendimento de carne significativamente maior que os homozigotos dominantes, e isso tem efeito significativo para a espessura de toucinho, mostrando que o genótipo $\mathrm{Hal}^{\mathrm{Nn}}$ é superior ao genótipo Hal $^{\mathrm{NN}}$, quanto à composição das carcaças (ANTUNES, 1997; De SMET et al., 1998). SATHER \& JONES, 1996, não encontraram diferença significativa na espessura de toucinho entre suínos com o genótipo halotano $\mathrm{Hal}^{\mathrm{NN}}$ e $\mathrm{Hal}^{\mathrm{Nn}}$. A espessura de músculo foi cerca de 5 milímetros maior nos suínos heterozigotos $\left(\mathrm{Hal}^{\mathrm{Nn}}\right)$; entretanto, a percentagem de carne foi $1 \%$ maior nos suínos heterozigotos $\left(\mathrm{Hal}^{\mathrm{Nn}}\right)$.

O genótipo halotano é o fator predominante na determinação da qualidade da carne em relação à condição PSE. Através das análises de $\mathrm{pH}$ inicial, refletância e perda de líquido, suínos recessivos para o gene halotano $\left(\mathrm{Hal}^{\mathrm{nn}}\right)$ foram sempre diferentes significativamente dos heterozigotos $\left(\mathrm{Hal}^{\mathrm{Nn}}\right)$ e dos normais $\left(\mathrm{Hal}^{\mathrm{NN}}\right)$. O pH inicial e a perda de líquido por gotejamento, dos suínos do genótipo halotano $\mathrm{Hal}^{\mathrm{Nn}} \mathrm{e} \mathrm{Hal}^{\mathrm{NN}}$ diferiram significativamente, sendo o $\mathrm{pH}$ inicial mais baixo nos suínos heterozigotos $\left(\mathrm{Hal}^{\mathrm{Nn}}\right)$ cuja carne também apresentou maior perda de líquido. A carne de suínos heterozigotos $\left(\mathrm{Hal}^{\mathrm{Nn}}\right)$ e homozigotos recessivos $\left(\mathrm{Hal}^{\mathrm{nn}}\right)$ caracteriza-se pela baixa retenção de água, e cor pálida quando comparada com a de suínos normais ( $\mathrm{Hal}^{\mathrm{NN}}$ ) (LUNDSTRÖM et al., 1989; SIMPSON \& WEBB, 1989; RUSSO et al., 1994; De SMET et al., 1996 e 1998; SATHER \& JONES, 1996).

Verificou-se, analisando o efeito do genótipo halotano, que suínos halotano positivos $\left(\mathrm{Hal}^{\mathrm{NN}}\right)$ apresentaram carcaça com maior porcentagem de carne, porém com qualidade de carne inferior quando comparados com suínos halotano negativos (De SMET et al., 1995; TAM $\boldsymbol{e t}$ al., 1998). Quanto ao $\mathrm{pH}$ final, nenhuma diferença entre os três genótipos tem sido observada (De SMET et al., 1998; TAM et al., 1998).
O objetivo deste trabalho foi avaliar o efeito do gene halotano sobre a qualidade da carcaça e da carne em animais portadores e animais livres do gene halotano

\section{MATERIAL E MÉTODOS}

Foram utilizadas meias carcaças direitas de 151 suínos híbridos comerciais. A coleta de dados foi realizada em três etapas representadas por três dias de abate dos suínos. Dos animais abatidos, foram escolhidas 31, 50 e 70 carcaças, com peso aproximado de $70 \mathrm{~kg}$, respectivamente, do primeiro, segundo e terceiro dia de abate em um matadouro-frigorífico comercial com inspeção federal.

Através da sonda de fibra óptica "GP4 Hennessy", foram obtidas a espessura de toucinho $(\mathrm{mm})$, espessura de músculo $(\mathrm{mm})$ e percentagem de carne. Após serem tipificadas eletronicamente, as carcaças foram pesadas e resfriadas por 24 horas entre 0 e $2^{\circ} \mathrm{C}$. Na câmara de resfriamento, foram realizadas as leituras de $\mathrm{pH}$. As medidas de $\mathrm{pH}$ foram realizadas no músculo longo torácico, na altura da décima costela, aos 45 minutos ( $\mathrm{pH}$ inicial) e 24 horas após o abate ( $\mathrm{pH}$ final).

Das carcaças que seguiram para o espostejamento, foi separado o lombo sendo retiradas duas chuletas de aproximadamente $2,5 \mathrm{~cm}$ de espessura, para a avaliação de cor, perda de líquido por gotejamento e obtenção de gordura para determinação do genótipo. A determinação da perda de líquido por gotejamento baseou-se na metodologia usada por OURIQUE (1989).

A avaliação da cor foi realizada na chuleta com auxílio de padrões fotográficos da Polyfilm - Divisão de Carnes, com cinco tonalidades de músculo longo dorsal, respectivamente, rosa muito pálido (1), rosa pálido (2), rosa cinzento (3), vermelho escuro (4) e vermelho muito escuro (5), conforme OURIQUE (1989).

Para a determinação do genótipo halotano, utilizou-se um par de oligonucleotídeos específico (MH-F,5'-GTTCCCTGTGTGTGTGCAATGGTG-3' e MH-R,5' - ATCTCTAGAGCCAGGGAGCAAGTT CTCAGTAAT-3') para a amplificação da seqüência de DNA do gene do receptor rianodina suíno (FUJII et al., 1991). Alíquotas de gordura de 30 a 50mg de cada amostra de carne suína foram colocadas em tubos e $200 \mu \ell$ de tampão 1 XPCR com $1,6 \mu \mathrm{g} / \mu \ell$ de Proteinase $\mathrm{K}^{\mathrm{b}}$, sendo incubadas a $56^{\circ} \mathrm{C}$ por 150 minutos e a $95^{\circ} \mathrm{C}$ por 20 minutos.

Após a incubação, $2 \mu \ell$ de cada amostra foram adicionados a tubos com $8 \mu \ell$ de uma solução 
contendo: $1 \mu \ell$ tampão 10XPCR $\left(20 \mathrm{mM} \mathrm{MgCl}_{2}\right.$, $500 \mathrm{mM} \mathrm{KCl} 2100 \mathrm{mM}$ Tris- $\mathrm{HCl} \mathrm{pH} 8,3) ; 1 \mu \ell$ da solução com $1,25 \mathrm{mM}$ de cada dNTP; $4 \mu \mathrm{g}$ de $\mathrm{BSA}^{\mathrm{c}}$; $0,5 \mathrm{U}$ de TaqDNA polimerase ${ }^{\mathrm{c}}$; 10 pmoles de cada oligonucleotídeo; e água ultrapura estéril. As amostras contendo o volume de $10 \mu \ell$ para reação e $30 \mu \ell$ de óleo mineral ${ }^{\mathrm{d}}$ foram acondicionadas no termociclador automático e submetidas ao seguinte protocolo de amplificação por PCR: a) $94^{\circ} \mathrm{C}$ por 5 minutos; b) 40 ciclos consecutivos de $94^{\circ} \mathrm{C}$ por 1 minuto, $56^{\circ} \mathrm{C}$ por 30 segundos e $72^{\circ} \mathrm{C}$ por 1 minuto; e c) $72^{\circ} \mathrm{C}$ por 8 minutos.

Após a amplificação do DNA de gordura suína por PCR, foram adicionados a cada amostra $10 \mathrm{U}$ de enzima Hha I, $2 \mu \ell$ de tampão de reação $10 \mathrm{X}$ Hha I e de água ultra pura estéril, perfazendo um volume final de $20 \mu \ell$. Os tubos foram submetidos à incubação à $37^{\circ} \mathrm{C}$ por 90 minutos e $65^{\circ} \mathrm{C}$ por 10 minutos. Os $20 \mu \ell$ de amostra, contendo o DNA amplificado por PCR e submetidos ao ensaio de restrição com Hha I, foram levados à eletroforese em gel de agarose 3\% em tampão TBE 0,5X (SAMBROOK et al., 1989).

A digestão do fragmento, com a enzima de restrição Hha I, produz dois fragmentos de 49 e $32 \mathrm{pb}$ para animais homozigotos normais $\left(\mathrm{Hal}^{\mathrm{NN}}\right)$, três fragmentos de 49, 32 e $81 \mathrm{pb}$ para heterozigotos $\left(\mathrm{Hal}^{\mathrm{Nn}}\right)$ e somente um fragmento de $81 \mathrm{pb}$ para indivíduos homozigotos mutantes $\left(\mathrm{Hal}^{\mathrm{nn}}\right)$.

Realizou-se análise de variância segundo o procedimento GLM (General Linear Methods) do programa estatístico SAS versão 6.11. Para todas as características analisadas, foi utilizado o peso da carcaça como covariável, e como tratamento a classificação pelo "Gp4 Hennessy" e o "genótipo halotano". O teste de Tukey foi utilizado para a comparação entre as médias.

\section{RESULTADOS E DISCUSSÃO}

De 151 carcaças analisadas, 61,59\% foram provenientes de suínos com genótipo halotano normal $\left(\mathrm{Hal}^{\mathrm{NN}}\right), 33,77 \%$ de carcaças de suínos heterozigotos $\left(\mathrm{Hal}^{\mathrm{Nn}}\right)$ e 4,64\% de carcaças de suínos com genótipo halotano recessivo $\left(\mathrm{Hal}^{\mathrm{nn}}\right)$. Considerando-se a probabilidade de $5 \%$, não houve diferença significativa entre os genótipos para a espessura de toucinho, concordando com SATHER \& JONES (1996). Observou-se, no entanto, que os suínos normais $\left(\mathrm{Hal}^{\mathrm{NN}}\right)$ apresentaram maior espessura de toucinho que os animais heterozigotos
$\left(\mathrm{Hal}^{\mathrm{Nn}}\right)$ para o gene halotano $(\mathrm{P}=0,06)$, concordando com ANTUNES (1997).

Os suínos heterozigotos $\left(\mathrm{Hal}^{\mathrm{Nn}}\right)$ apresentaram maior espessura de músculo do que os animais normais, sendo esta diferença significativa $(\mathrm{P}=0,015)$, concordando com SATHER \& JONES (1996). Não se observou diferença significativa $(\mathrm{P}<0,05)$ na medida de espessura de músculo entre animais recessivos $\left(\mathrm{Hal}^{\mathrm{nn}}\right)$ e heterozigotos $\left(\mathrm{Hal}^{\mathrm{Nn}}\right)$ para o gene halotano (Tabela 1).

Considerando-se o total de carcaças, verificou-se que a percentagem média de carne foi de $47,53 \%$ ( \pm 6,91). Suínos heterozigotos apresentaram maior percentagem de carne do que suínos normais sendo esta diferença significativa $(\mathrm{P}=0,048)$ e não diferindo significativamente dos suínos recessivos (Tabela 1), concordando com ANTUNES (1997). De SMET et al. (1998) relataram que o conteúdo de carne foi maior nas carcaças de suínos recessivos para o gene halotano, seguido dos suínos heterozigotos $\left(\mathrm{Hal}^{\mathrm{Nn}}\right)$ e menor nos suínos normais, sendo que esta característica nos suínos heterozigotos, está mais próxima dos suínos recessivos $\left(\mathrm{Hal}^{\mathrm{nn}}\right)$ do que dos suínos normais. No entanto, SATHER \& JONES (1996) encontraram semelhanças entre suínos normais e heterozigotos $\left(\mathrm{Hal}^{\mathrm{NN}}\right.$ e $\mathrm{Hal}^{\mathrm{Nn}}$ ). Os autores observaram que suínos heterozigotos apresentaram somente $1 \%$ a mais de percentagem de carne em relação aos homozigotos enquanto no presente trabalho suínos heterozigotos apresentaram diferença de $2,38 \%$ a mais de percentagem de carne do que em suínos normais.

A média de peso das carcaças quentes foi de 70,10kg ( $\pm 13,95)$, não havendo diferença significativa $(\mathrm{P}<0,05)$ entre os genótipos quanto a esta característica (Tabela 1), resultado que concorda com os encontrados por SATHER et al. (1991) e ANTUNES (1997).

Tabela 1 - Médias e desvio padrão das medidas quantitativas de carcaças suínas segundo o genótipo halotano.

\begin{tabular}{clccc}
\hline \multirow{2}{*}{ Variáveis quantitativas } & & \multicolumn{3}{c}{ Genótipo Halotano } \\
\cline { 3 - 5 } & & $\mathrm{Hal}^{\mathrm{NN}}$ & $\mathrm{Hal}^{\mathrm{Nn}}$ & $\mathrm{Hal}^{\mathrm{nn}}$ \\
\hline \multirow{2}{*}{ Espessura de toucinho (mm) } & Média & $24,39 \mathrm{a}$ & $21,56 \mathrm{a}$ & $22,40 \mathrm{a}$ \\
& DP & 9,33 & 7,49 & 8,18 \\
Espessura de músculo (mm) & Média & $39,28 \mathrm{a}$ & $42,55 \mathrm{~b}$ & $43,94 \mathrm{~b}$ \\
& DP & 9,73 & 9,27 & 11,73 \\
Percentagem de carne (\%) & Média & $46,63 \mathrm{a}$ & $49,01 \mathrm{~b}$ & $48,70 \mathrm{~b}$ \\
& DP & 7,34 & 5,95 & 6,34 \\
Peso da carcaça quente (kg) & Média & $70,22 \mathrm{a}$ & $69,82 \mathrm{a}$ & $70,59 \mathrm{a}$ \\
& DP & 14,17 & 13,09 & 12,96 \\
& & & & \\
\hline
\end{tabular}

Médias seguidas da mesma letra não diferem estatisticamente $(\mathrm{P}<0,05)$.

$\mathrm{DP}=$ desvio padrão. 
O pH inicial do músculo Longissimus dorsi foi mais baixo nos suínos portadores do gene halotano $\mathrm{Hal}^{\mathrm{Nn}}$ e $\mathrm{Hal}^{\mathrm{nn}}$, não havendo diferença entre os suínos recessivos e heterozigotos (Tabela 2), concordando com De SMET et al. (1998). Entretanto, observou-se diferença significativa $(\mathrm{P}=0,003)$ nos valores de $\mathrm{pH}$ inicial do músculo Longissimus dorsi entre os suínos normais e heterozigotos, concordando com SATHER \& JONES (1996), De SMET et al. (1996, 1998) e TAM et al. (1998). Estes resultados mostram que o gene halotano exerce influência sobre o $\mathrm{pH}$ inicial e, mesmo em heterozigose, provocou diminuição dos valores de $\mathrm{pH}$ inicial, propiciando com isto tendência a produzir uma frequiência maior de carnes PSE. Estes resultados estão de acordo com RUSSO et al. (1994), SATHER \& JONES (1996) e De SMET et al. (1998). O pH final das carcaças não diferiu $(\mathrm{P}<0,05)$ entre os três genótipos halotano (Tabela 2), mostrando que o genótipo halotano não influenciou o $\mathrm{pH}$ final, concordando com De SMET et al. (1998) e com TAM et al. (1998).

A média de perda de líquido por gotejamento foi maior nos suínos recessivos; porém, não diferiu $(\mathrm{P}<0,05)$ dos demais, discordando de RUSSO et al. (1994) e De SMET et al. (1996), que encontraram diferenças significativas entre os genótipos. A média geral atribuída à cor foi de 2,41 $( \pm 0,56)$, um pouco mais clara do que o escore normal, igual a 3,0. A chuleta dos suínos portadores do gene halotano foi mais clara, porém, não houve distinção entre os dois genótipos $\mathrm{Hal}^{\mathrm{Nn}}$ e $\mathrm{Hal}^{\mathrm{nn}}(\mathrm{P}>$ $0,05)$. As chuletas dos suínos heterozigotos $\left(\mathrm{Hal}^{\mathrm{Nn}}\right)$ e recessivos $\left(\mathrm{Hal}^{\mathrm{nn}}\right)$ apresentaram coloração mais clara que as dos animais normais, sendo esta diferença significativa $(\mathrm{P}=0,0012)$ (Tabela 2$)$, concordando

Tabela 2 - Médias e desvio padrão das variáveis qualitativas analisadas em carcaças suínas segundo o genótipo halotano.

\begin{tabular}{lllll}
\hline \multirow{2}{*}{ Variáveis quantitativas } & & \multicolumn{3}{c}{ Genótipo halotano } \\
\cline { 3 - 5 } & & $\mathrm{Hal}^{\mathrm{NN}}$ & $\mathrm{Hal}^{\mathrm{Nn}}$ & $\mathrm{Hal}^{\mathrm{nn}}$ \\
\hline \multirow{2}{*}{$\mathrm{pH}$ inicial } & média & $5,91 \mathrm{a}$ & $5,71 \mathrm{~b}$ & $5,68 \mathrm{~b}$ \\
& DP & 0,40 & 0,31 & 0,22 \\
$\mathrm{pH}$ final & Média & $5,39 \mathrm{a}$ & $5,42 \mathrm{a}$ & $5,53 \mathrm{a}$ \\
& DP & 0,30 & 0,34 & 0,25 \\
Cor & Média & $2,54 \mathrm{a}$ & $2,24 \mathrm{~b}$ & $2.00 \mathrm{~b}$ \\
\multirow{2}{*}{$\begin{array}{l}\text { Perda de líquido por gotejamento } \\
(\%)\end{array}$} & DP & 0,40 & 0,70 & 0,60 \\
& Média & $1,48 \mathrm{a}$ & $1,59 \mathrm{a}$ & $1,73 \mathrm{a}$ \\
& DP & 0,96 & 0,84 & 0,90 \\
\hline
\end{tabular}

Médias seguidas da mesma letra não diferem estatisticamente $(\mathrm{P}<0,05)$.

$\mathrm{DP}=$ desvio padrão. com LUNDSTROM et al. (1989), SIMPSON \& WEBB (1989), SATHER et al. (1991), RUSSO $\boldsymbol{e}$ al. (1994) e De SMET et al. (1995).

\section{CONCLUSÕES}

Nas condições do presente trabalho, os resultados obtidos permitem concluir que: Os suínos com genótipo halotano $\mathrm{Hal}^{\mathrm{Nn}}$ apresentaram maior espessura de músculo e percentagem de carne do que os suínos do genótipo halotano $\mathrm{Hal}^{\mathrm{NN}}$, porém exibiram uma qualidade de carne inferior à dos suínos $\mathrm{Hal}^{\mathrm{NN}} \mathrm{O} \mathrm{pH}$ inicial foi mais baixo nos suínos portadores do gene halotano $\mathrm{Hal}^{\mathrm{Nn}}$ e $\mathrm{Hal}^{\mathrm{nn}}$, não havendo diferença estatística entre eles. A cor da carne foi mais pálida nos suínos portadores do gene halotano $\left(\mathrm{Hal}^{\mathrm{Nn}}\right.$ e $\mathrm{Hal}^{\mathrm{nn}}$ ), mas sem diferença entre eles. $\mathrm{O}$ pH final não esteve relacionado com $\mathrm{o}$ genótipo halotano.

\section{FONTES DE AQUISIÇÃO}

${ }^{a}$ DIDAI Tecnologia Ltda. SP. Brasil.

${ }^{\text {b }}$ GIBCOBRL, 25530-015

${ }^{\mathrm{c}}$ Cenbiot $^{\circledR} / \mathrm{RS}$

${ }^{\mathrm{d}}$ Sigma ${ }^{\circledR}$, M-5904

\section{REFERÊNCIAS BIBLIOGRÁFICAS}

ANTUNES, R.C. O efeito do genótipo hal sobre o rendimento de carne em partes da carcaça de suínos cruzados. Uberlândia : 1997. 64p. Dissertação (Mestrado em Genética e Bioquímica) - Programa de Pós-graduação em Genética e Bioquímica, Universidade Federal de Uberlândia, Uberlândia, 1997.

De SMET, M.S.; PAUWELS, H.; VERVAEKE, I., et al. Meat and carcass quality of heavy muscled belgian slaughter pigs as influenced by halothane sensitivity and breed. Animal Science, Barking, v.61, n.1, p.109-114, 1995.

De SMET, M.S.; PAUWELS, H.; De BIE, S., et al. Effect of halothane genotype, breed, feed withdrawal, and lairage on pork quality of belgian slaughter pigs. Journal of Animal Science, Champaign, v.74, n.8, p.1854-1863, 1996.

De SMET, S.; BLOEMEN, H.; VOORDE, G., et al. Meat and carcass quality in two pigs lines of different stresssusceptibility genotype and their crosses. Animal Science, Barking, v.66, n.2, p.441-447, 1998.

FUJII, J.; OTSU, K.; ZORZATO`F., et al. Identification of a mutation in porcine ryanodine receptor associated with malignant hyperthermia. Science, Washington, v.253, p.448$451,1991$.

LUNSDTRÖM, K.; ESSÉN-GUSTAVSSON, B.; RUNDGREN, M., et al. Effect of halothane genotype on muscle metabolism at slaughter and its relationship with meat quality: a within-litter comparison. Meat Science, Barking, v.25, p.251-263, 1989. 
OURIQUE, J.M.R. Características físico-químicas e organolépticas e suas relações na avaliação de qualidade da carne suína. Porto Alegre, 1989. 104p. Dissertação (Mestrado em Agronomia - Zootecnia) - Programa de Pósgraduação em Agronomia, Universidade Federal do Rio Grande do Sul, Porto Alegre, 1989.

RUSSO, V., NANNI, C.L., DALL'OLIO, S. Effect of the halothane gene in heterozygote pigs on ham meat quality. In: INTERNATIONAL CONGRESS OF MEAT SCIENCE AND TECHNOLOGY, 40, 1994, The Hague. Abstracts... The Hague : ICoMST, 1994. p.45.

SAMBROOK, J., FRITSCH, E.F., MANIATIS, T. Molecular cloning: a laboratory manual. 2ed. New York : Cold Spring Harbor Laboratory, 1989. v.3.
SATHER, A.P., JONES, S.D.M., TONG, A.K.W. Halothane genotype by weight interactions on pig meat quality. Canadian Journal of Animal Science, Ottawa, v.71, n.3, p.645-658, 1991.

SATHER, A.P., JONES, S.D.M. The effect of genotype on feedlot performance, carcass composition, and lean meat quality from commercial pigs. Canadian Journal of Animal Science, Ottawa, v.76, n.4, p.507-516, 1996.

SIMPSON, S.P., WEBB, A.J. Growth and carcass performance of british landrace pigs heterozigous at the halothane locus. Animal Production, Edinburgh, v.49, n.3, p.503-509, 1989.

TAM, L.G., BERG, E.P., GERRARD, D.E. Effect of halothane genotype on porcine meat quality and myoglobin antioxidation. Meat Science, Barking, v.49, n.1, p.41-53, 1998. 